\title{
Comparative Efficacy of Sutures and Suture less Techniques for Gastrotomy Incision closure in Dog
}

\author{
Nasir Igbal ${ }^{1 *}$, Naveed Hussain ${ }^{1}$, Muhammad Atif ${ }^{1}$, Sadaf Aslam $^{1}$, Hamza Jawad ${ }^{2}$, Zubair \\ Lugman ${ }^{2}$, Ayesha SadiQ 3 , Zahra Ashraf ${ }^{5}$, Haroon AKbar ${ }^{4}$
}

${ }^{1}$ Department of Veterinary Surgery \& $\mathcal{F}^{3}$ et Sciences, University of Veterinary and Animal Sciences, Lahore, Punjab, Pakistan; ${ }^{2}$ Faculty of Veterinary and Animal Sciences, The Islamia University of Bahawalpur, Bahawalpur, Punjab, Pakistan; ${ }^{3}$ Department of Pathology, University of Veterinary and Animal Sciences, Lahore, Punjab, Pakistan; ${ }^{4}$ Department of Parasitology, University of Veterinary and Animal Sciences, Lahore, Punjab, Pakistan; ${ }^{5}$ Faculty of Veterinary Science, University of Agriculture Faisalabad, Faisalabad, Punjab, Pakistan.

\begin{abstract}
Gastrotomy is suggested in case of gastric dilatation with volvolus, gastric foreign bodies, gastric retention, out flow obstruction, hypertrophic gastropathy, gastric neoplasia, and gastro duodenal ulceration. Different techniques are considered to close gastric incisions like absorbable suturing material, stapler suture and use of adhesive glue. These techniques give different kind of effects on gastrotomy closure. The present study was carried out on 12 adult mongrel dogs with an average of 15 to $20 \mathrm{~kg}$ body weight. They were divided into three groups, each group having 4 animals and designated as group A, B and C. Standard Gastrotomy procedure was performed in group A (sutured as, first layer by simple continuous pattern followed by $2^{\text {nd }}$ layer of cushing sutures with Vicryl \#1), B Linear Stapler , (Linear Gastric Stapler, Ethicon, Inc. Johnson and Johnson, USA) was used to close gastric incision while in group $\mathrm{C}$ gastrotomy site was closed by tissue adhesive glue Cyanoacrylate (Dermabond 0.5ml, Ethicon, Inc. Johnson and Johnson, USA). Comparison of all suturing and suture less techniques was carried out through Physical evaluation, food, water intake and defecation, Weight loss / gain, Complete Blood Count, Leakage evaluation by contrast radiography and postmortem findings. It was concluded that suturing technique (using absorbable suture material in two layers) considered much better than other two methods (adhesive glue and stapling) economically, due to use of ease and least post-operative complication. The results of this study will help veterinarian, field workers and pet practioners to use suturing technique as most effective and appropriate technique for gastrotomy closure in terms of better healing, less blood loss and least chances of post operation complications.
\end{abstract}

Keywords | Gastrotomy, Conventional Sutures, Stapler, Glue, Complication.

Received | June 26, 2020; Accepted | July 05, 2020; Published | November 15, 2020

*Correspondence | Nasir Iqbal, Department of Veterinary Surgery \& Pet Sciences, University of Veterinary and Animal Sciences, Lahore, Punjab, Pakistan; Email: nasir.iqbal@uvas.edu.pk

Citation | Iqbal N, Hussain N, Atif M, Aslam S, Jawad H, Luqman Z, Sadiq A, Ashraf Z, Akbar H (2020). Comparative efficacy of sutures and suture less techniques for gastrotomy incision closure in dog. Adv. Anim. Vet. Sci. 8(12): 1294-1300.

DOI | http://dx.doi.org/10.17582/journal.aavs/2020/8.12.1294.1300

ISSN (Online) | 2307-8316; ISSN (Print) | 2309-3331

Copyright (C) 2020 Iqbal et al. This is an open access article distributed under the Creative Commons Attribution License, which permits unrestricted use, distribution, and reproduction in any medium, provided the original work is properly cited.

\section{INTRODUCTION}

$\mathrm{S}_{\mathrm{i}}^{\mathrm{s}}$ omach is the largest dilatation of gastrointestinal tract in canines which initiates digestion and also serves as reservoir of food. The empty organ adopts more J shapes, whereas the full is a more constant $\mathrm{C}$ shape (Slatter, 2003). Stomach inlet from esophagusis called cardia while outlet to duodenum is the pylorus, having cardiac and pyloric sphincters respectively. Stomach part closest to the cardia is fundus, which is bulging in shape while the restis smaller in size and named as body. Gastric folds on the interior surface help to grind and digest food while glands in the wall secrete gastric juices and hydrochloric acid which help to digest protein and fats (Coolman et al., 2000).Various surgical anomalies of the stomach include: gastric dilatation with volvolus, foreign bodies, gastric out flow obstruc- 
tion, hypertrophic gastropathy, motility disorders, neoplasia, gastro esophageal intussusceptions and perforation that may require gastrotomy (Formaggini et al., 2018). Gastrotomy closure techniques are very crucial, which help to avoid post-operative complication e.g. peritonitis. Different techniques may be considered to close gastric incisions including conventional suturing methods, stapling technique and use of adhesive glue (Sogi et al, 2019). Two-layered conventional suturing pattern with absorbable suture materials are used to decrease intra luminal bleeding and making a secure seal for closure of gastric incision. First suture layer should be continuous pattern and it should oppose mucosa while second one must incorporate sub mucosal, muscular and serosal layers in either a Cushing or Lambert suture pattern (DePompeo et al., 2003).The use of stapling equipment is now well accepted in small animal surgical practice. Several factors like affordability, simplicity of use and significant decrease in surgery and anesthesia time have increased popularity of staplers (Belandria et al., 2009). An effective adhesive chemical as aide in surgery is cyanoacrylate (Schwartz et al., 2018). Their usage in surgical practices has become popular especially during closure of skin. cyanoacrylate makes strong union of tissues through anionic polymerization within couple of minutes (Wintrobe, 2008). This adhesion develops due to molecular magnetism and mechanical hold of porous surfaces (Eason et al., 2017).

So, the present project was designed to evaluate the comparative efficacy of suturing technique with sutureless techniques i.e. conventional suturing techniques, linear tissue stapler and adhesive glue with special emphasis on procedure effectiveness in terms of easy approach, improving stomach diameter, healing of surgical site and least post-operative complications (Cerdá et al., 2015).

\section{MATERIALS AND METHODS}

\section{Animal Selection and Experimental Design}

The present project was designed to compare different gastrotomy closure techniques in dogs. The study was carried on 12 randomly selected male/female mongrel dogs, having age between six months to two years. The dogs were further classified into three subgroups named as group A, B and C' each group having 4 dogs which were numbered 1-4, 5-8 and 9-12 respectively. Dogs of group A were subjected to conventional standard double layer suturing (as described by Slatter, 2003) by using vicryl\# 1 . For group B, linear stapler (Linear Gastric Stapler, Ethicon, Inc. Johnson and Johnson, USA) was used to close gastric incision while in group $\mathrm{C}$ gastrotomy site was closed by tissue adhesive glue Cyanoacrylate (Dermabond 0.5ml, Ethicon, Inc. Johnson and Johnson, USA). The surgery was performed through ventral midline laparotomy from xiphiod to umbilicus to a variable distance caudally under general anesthesia.

\section{Pre-Operation Clinical Examination}

All animals underwent a thorough physical examination and complete blood count prior tostudies to rule out any pre-operative problem. Dogs were examined and treated for possible external and internal parasites. For dirt and ectoparasites, they were bathed with "Omni guard shampoo" (Omni-guard)" and endoparasites were treated by " canine-dewormer " (safe-guard) at dose rate of $50 \mathrm{mg} / \mathrm{kg}$ for 3 consecutive days. Rabisin vaccine (Merial) was give as prophylaxis@1ml per animal (SC). Antibiotic "Cephradin"(Velosef) at dose rate of $40 \mathrm{mg} / \mathrm{kg}$ (IM) was given preoperative for 5 days to minimize risk of systemic infection.

\section{Premedication And Anesthesia}

Xylazine HCL, as pre-anesthetic was givenat dose rate of $0.1-1 \mathrm{mg} / \mathrm{kg}$ (IM). For sedation, drugs of xylazine, ketamine and atropine sulphate $(2.2 \mathrm{mg} / \mathrm{kg}+10 \mathrm{mg} / \mathrm{kg}+0.04$ $\mathrm{mg} / \mathrm{kg}$ respectively) were administered (IM). During gastrotomy, general anesthesia was maintained with propofol at the dose of $0.1-0.4 \mathrm{mg} / \mathrm{kg} / \mathrm{min}$ by intravenous route as CRI (continuous rate infusion) (Sog et al., 2019).

\section{Surgical Procedure and Gastrotomy Closure Techniques}

Gastrotomy procedure was performed for group A, B and C as described by Slatter (Slatter, 2003). After performing surgery, the stomach of dogs in group A were sutured in two layers i.e. First layer of simple continuous pattern followed by $2^{\text {nd }}$ layer of cushing sutureswith Vicryl \#1. For group B, linear skin stapler "Reflex-one skin stapler" (ConMed) was used to close gastric incision and in group C gastrotomy site was closed by Cyanoacrylate glue"Dermabond $^{\text {" }}$ (Ethicon). After the surgery dogs were kept on IV line for 5 days for feeding. Antibiotics and NSAIDS were given for 7 days for complete healing of gastrotomy incision.

\section{Post-Operative Evaluation of Gastrotomy Closure Technique}

Following parameters were used in the experiment to find out the best possible procedure in term of prompt healing with least possible complications as well as less time spent on procedures i.e.,

\section{Physical Evaluation}

Stomach was topographically palpated on left side of abdominal wall for general examination purposes. Temperature, pulse and respiration was monitored at specific intervals to evaluate any kind of inflammation/infection during study period. 
Hematological Evaluations

Blood was collected in anticoagulant containing test tubes for hematological analysis including WBCs count, RBCs count and $\mathrm{Hb}$ concentration to monitor any kind of infection or anemia due to blood loss. Hematology Veterinary Analyzer (Abacus Junior Vet CBC Analyzer 2001) was used for this purpose in University Diagnostic Lab(UDL), University of Veterinary \& Animal Sciences, Lahore

\section{Body WeIght Gain/Loss}

Body weight was examined on weigh machine "Accurate Plus scale system ${ }^{\circledR}-$ Yaohua YH-T6B" in surgery section, University of Veterinary \& Animal Sciences, Lahore on specified days during trial

\section{Leakage Evaluation (By Contrast Radiography)}

Contrast radiography was used at different days post-surgery to check any kind of leakage i.e. iodinated contrast media "MD-Gastroview"(Guerbet) @ 90ml was administered (PO). Digital x-ray machine (Collimator Type R-20J 2015 SHIMADZU CORPORATION) at pet center, UVAS, Lahore was used for this purpose.

\section{Statistical Analysis}

All values are expressed as mean \pm S.E. Initial data compilation was managed by use of MS Excel. Difference between means was detected by using analysis of variance(ANOVA) with Minitab software V 16

\section{RESULTS}

\section{Physical Evaluation}

\section{Topographic Approach for Stomach}

Stomach was palpated on left side of abdominal wall for any kind of pain or other gross abnormality. It was observed that palpation showed remarkable pain for first week of surgery. Pain gradually reduced with passage of time and no pain was felt on palpation after day 30 in any animal. No external abdominal wall lesions, swelling or any other gross abnormality was seen in any dog during trial period.

\section{TEMPERATURE}

Table 1: Comparative Mean Values of Temperature for Group A, B and C

\begin{tabular}{llll}
\multirow{4}{*}{ Days } & \multicolumn{3}{l}{ Temperature $\left({ }^{\circ} \mathbf{F}\right)$} \\
& Group A & Group B & Group C \\
& Mean \pm S.D & Mean \pm S.D & Mean \pm S.D \\
\hline $\mathbf{1}$ & $104.0 \pm 1.38$ & $103.2 \pm 1.31$ & $103.6 \pm 1.33$ \\
3 & $103.2 \pm 1.30$ & $103.0 \pm 1.30$ & $103.4 \pm 1.32$ \\
\hline 5 & $102.6 \pm 1.24$ & $102.8 \pm 1.28 *$ & $102.8 \pm 1.26$ \\
7 & $102.8 \pm 1.25$ & $102.6 \pm 1.25$ & $102.5 \pm 1.29$ *** \\
\hline
\end{tabular}

$\begin{array}{llll}15 & 102.0 \pm 1.23 & 101.8 \pm 1.22 & 102.5 \pm 1.25 \\ 30 & 101.8 \pm 1.22 & 101.8 \pm 1.20 & 101.8 \pm 1.23 \\ 45 & 100.4 \pm 1.17 & 100.6 \pm 1.18 & 101.4 \pm 1.21 \\ 60 & 100.6 \pm 1.19 & 100.8 \pm 1.19 & 101.4 \pm 1.22\end{array}$

* Dog \# 8 of Group B died at Day $5^{\text {th }}$ of Experiment.

** Dog \# 11 of Group Cdied at Day $7^{\text {th }}$ of Experiment.

Values of body temperature at different days revealed that there was slight increase in temperature for first 5 days which was due to inflammation caused by laprotomy and associated gastric surgical procedures. Temperature became stable after day 7 and gradually returned to normal levels till end of trial.

\section{Pulse}

Table 2: Comparative Mean Values of Pulse for Group A, $\mathrm{B}$ and $\mathrm{C}$

\begin{tabular}{|llll} 
Days & $\begin{array}{l}\text { Pulse (/ min) } \\
\text { Group A }\end{array}$ & Group B & Group C \\
& Mean \pm S.D & Mean \pm S.D & Mean \pm S.D \\
\hline $\mathbf{1}$ & $76 \pm 2.01$ & $72 \pm 1.68$ & $70 \pm 1.53$ \\
\hline 3 & $74 \pm 1.82$ & $76 \pm 2.03$ & $76 \pm 2.02$ \\
\hline 7 & $76 \pm 2.00$ & $73 \pm 1.74^{*}$ & $78 \pm 2.18$ \\
\hline 15 & $78 \pm 2.14$ & $75 \pm 1.92$ & $75 \pm 1.94^{* *}$ \\
\hline 30 & $75 \pm 1.94$ & $77 \pm 2.11$ & $72 \pm 1.66$ \\
\hline 45 & $75 \pm 1.96$ & $74 \pm 1.84$ & $75 \pm 1.94$ \\
60 & $78 \pm 2.17$ & $74 \pm 1.85$ & $76 \pm 2.01$ \\
\hline & $80 \pm 2.21$ & $75 \pm 1.95$ & $79 \pm 2.19$ \\
\hline
\end{tabular}

* Dog \# 8 of Group B died at Day $5^{\text {th }}$ of Experiment.

** Dog \# 11 of Group Cdied at Day $7^{\text {th }}$ of Experiment.

Pulse values indicated that it remained stable and within normal range for all groups during whole of the experiment.

\section{RESPIRATION}

Table 3: Comparative Mean Values of Respiration for Group A, B and C.

\begin{tabular}{llll} 
Days & \multicolumn{2}{l}{ Respiration $(/$ min $)$} \\
& Group A & Group B & Group C \\
& Mean \pm S.D & Mean \pm S.D & Mean \pm S.D \\
\hline 1 & $27 \pm 1.13$ & $19 \pm 1.09$ & $25 \pm 1.11$ \\
3 & $30 \pm 1.16$ & $22 \pm 1.10$ & $28 \pm 1.18$ \\
\hline 5 & $28 \pm 1.17$ & $25 \pm 1.11^{*}$ & $27 \pm 1.14$ \\
7 & $26 \pm 1.12$ & $27 \pm 1.14$ & $25 \pm 1.12$ ** \\
15 & $27 \pm 1.13$ & $25 \pm 1.12$ & $27 \pm 1.13$ \\
30 & $25 \pm 1.10$ & $23 \pm 1.06$ & $24 \pm 1.08$ \\
45 & $24 \pm 1.08$ & $21 \pm 1.03$ & $25 \pm 1.11$ \\
60 & $24 \pm 1.09$ & $24 \pm 1.08$ & $25 \pm 1.10$
\end{tabular}

* Dog \# 8 of Group B died at Day $5^{\text {th }}$ of Experiment.

** Dog \# 11 of Group Cdied at Day $7^{\text {th }}$ of Experiment.

Respiration values remained within normal range for all groups during complete trial. 
Hematological Evaluation

White Blood Cells

Table 4: Comparative Mean Values of WBCs $\left(10^{3} / \mu 1\right)$ for Group A, B and C

\begin{tabular}{llll} 
Days & $\begin{array}{l}\text { Animals } \\
\text { Group A }\end{array}$ & Group B & Group C \\
& Mean \pm S.D & Mean \pm S.D & Mean \pm S.D \\
\hline 1 & $16.77 \pm 1.60$ & $15.81 \pm 1.12$ & $16.67 \pm 1.44$ \\
\hline 3 & $21.46 \pm 1.28$ & $23.56 \pm 0.93$ & $21.11 \pm 1.01$ \\
\hline 5 & $19.20 \pm 1.09$ & $23.33 \pm 0.56^{*}$ & $22.34 \pm 0.94$ \\
\hline 7 & $18.68 \pm 1.05$ & $22.67 \pm 0.71$ & $21.87 \pm 0.72 * *$ \\
15 & $16.66 \pm 0.99$ & $22.68 \pm 0.67$ & $19.07 \pm 0.95$ \\
\hline 30 & $16.24 \pm 0.60$ & $21.83 \pm 0.68$ & $19.21 \pm 0.81$ \\
\hline 45 & $15.02 \pm 0.77$ & $19.83 \pm 0.93$ & $17.68 \pm 0.72$ \\
\hline 60 & $15.76 \pm 0.58$ & $17.46 \pm 0.69$ & $16.40 \pm 0.51$ \\
\hline
\end{tabular}

* Dog \# 8 of Group B died at Day 5th of Experiment.

** Dog \# 11 of Group Cdied at Day $7^{\text {th }}$ of Experiment.

White blood cells level remained elevated from day 3 to day 7 in group $\mathrm{A}$ and $\mathrm{C}$ and subsequently declined to normal levels till end of trial. $\mathrm{WBCs}$ in group $\mathrm{B}$ remained at persistently upper level till day $30 \&$ showed gradual decrease till day 60 . Values of Group B indicate the occurrence of gastric infection/ contamination, group $\mathrm{C}$ was at moderate levels while group $\mathrm{A}$ was showed least contamination/infection.

\section{Red Blood Cells}

Table 5: Comparative Mean Values of RBCs $\left(10^{6} / \mu \mathrm{l}\right)$ for Group A, B and C

\begin{tabular}{llll} 
Days & $\begin{array}{l}\text { Animals } \\
\text { Group A } \\
\end{array}$ & Group B & Group C \\
& Mean \pm S.D & Mean \pm S.D & Mean \pm S.D \\
1 & $6.27 \pm 0.69$ & $6.21 \pm 0.40$ & $6.37 \pm 0.91$ \\
3 & $5.95 \pm 0.78$ & $6.06 \pm 0.41$ & $5.03 \pm 0.21$ \\
\hline 5 & $5.72 \pm 0.73$ & $5.60 \pm 0.24^{*}$ & $5.86 \pm 0.20$ \\
7 & $5.89 \pm 0.67$ & $5.12 \pm 0.22$ & $5.82 \pm 0.23 * *$ \\
\hline 15 & $6.64 \pm 0.62$ & $4.83 \pm 0.21$ & $5.65 \pm 0.27$ \\
30 & $6.45 \pm 0.57$ & $4.61 \pm 0.25$ & $5.79 \pm 0.16$ \\
45 & $6.44 \pm 0.52$ & $5.02 \pm 0.27$ & $6.53 \pm 0.29$ \\
60 & $6.18 \pm 0.50$ & $5.36 \pm 0.27$ & $6.37 \pm 0.26$ \\
\hline
\end{tabular}

* Dog \# 8 of Group B died at Day 5th of Experiment.

** Dog \# 11 of Group Cdied at Day $7^{\text {th }}$ of Experiment.

RBC values revealed that Group A showed best results as its values were consistent and gradually elevated from day 7 to end of trial. Group B values started decline from day 5 to day 30 and the raised slightly till day 60 . In group $\mathrm{C} \mathrm{RBC}$ value declined at day 3 , slightly raised $\&$ fluctuated from day 5 to day 30 and eventually elevated till end of experiment.

\section{HEMOGLOBIN}

Table 6: Comparative Mean Values of Hemoglobin (g/dl) for Group A, B and C

$\begin{array}{llll}\text { Days } & \begin{array}{l}\text { Animals } \\ \text { Group A } \\ \end{array} & \begin{array}{l}\text { Group B } \\ \text { Mean } \pm \text { S.D }\end{array} & \begin{array}{l}\text { Mean } \pm \text { S.D } \\ \text { Mean } \pm \text { S.D }\end{array} \\ 1 & 16.11 \pm 1.20 & 15.76 \pm 0.87 & 15.81 \pm 0.96 \\ 3 & 15.86 \pm 0.60 & 15.18 \pm 0.72 & 14.55 \pm 1.15 \\ 5 & 15.19 \pm 0.59 & 14.29 \pm 0.64 * & 14.94 \pm 0.46 \\ 7 & 15.48 \pm 0.45 & 14.06 \pm 0.56 & 14.88 \pm 0.50 * \\ 15 & 16.47 \pm 0.48 & 13.65 \pm 0.50 & 14.56 \pm 0.53 \\ 30 & 16.25 \pm 0.51 & 13.42 \pm 0.45 & 14.79 \pm 0.51 \\ 45 & 16.22 \pm 0.39 & 14.46 \pm 0.46 & 15.38 \pm 0.54 \\ 60 & 15.96 \pm 0.38 & 14.89 \pm 0.38 & 15.16 \pm 0.54\end{array}$

* Dog \# 8 of Group B died at Day 5th of Experiment.

* Dog \# 11 of Group Cdied at Day $7^{\text {th }}$ of Experiment.

Haemoglobin values indicate that values of Group A slightly fluctuated up to day 7 and then rose from day $15 \&$ remained persistent till day 60 . Group B values gradually slightly declined till day $30 \&$ then elevated slightly till end of trial. Group C relatively showed persistence for the whole period with slight elevation seen towards end of experiment.

\section{Body WeIGHT}

Table 7: Comparative Mean Values of Body Weight $(\mathrm{kg})$ For Group A, B and C

\begin{tabular}{|llll} 
Days & $\begin{array}{l}\text { Animals } \\
\text { Group A } \\
\text { Mean } \pm \text { S.D }\end{array}$ & $\begin{array}{l}\text { Group B } \\
\text { Mean } \pm \text { S.D }\end{array}$ & Group C \\
& Mean \pm S.D \\
\hline 1 & $15.25 \pm 1.83$ & $14.56 \pm 0.92$ & $14.62 \pm 2.06$ \\
3 & $14.77 \pm 1.79$ & $14.27 \pm 0.89$ & $14.05 \pm 2.04$ \\
\hline 5 & $14.36 \pm 1.83$ & $13.95 \pm 0.90 *$ & $13.88 \pm 2.05$ \\
\hline 7 & $14.30 \pm 1.80$ & $13.66 \pm 0.88$ & $13.82 \pm 1.97$ *** \\
\hline 15 & $14.50 \pm 1.66$ & $13.42 \pm 0.91$ & $14.06 \pm 1.93$ \\
\hline 30 & $14.81 \pm 1.77$ & $13.80 \pm 1.00$ & $14.18 \pm 1.87$ \\
45 & $15.06 \pm 1.78$ & $13.96 \pm 0.90$ & $14.38 \pm 2.01$ \\
60 & $15.54 \pm 1.78$ & $14.01 \pm 0.79$ & $14.12 \pm 2.00$ \\
\hline
\end{tabular}

* Dog \# 8 of Group B died at Day 5th of Experiment.

** Dog \# 11 of Group Cdied at Day $7^{\text {th }}$ of Experiment.

Values of body weight indicate that Group A showed better results in weight gain, its weight dropped till day 7 then dogs started regaining it till end of trial, even average weight increased than original weight till end of trial. Group B showed sharp decrease till day 15, then slight increase was observed till end of experiment. Group $\mathrm{C}$ also showed pattern like Group A till day 7 , onward slight increase was seen till day $45 \&$ then again slight decrease seen till day 60 .

LEAKAGE

Contrast Evaluation: The radiographs were taken at 
Day1, 3, 5, 7, 15, 30, 45 and 60 post-surgery respectively with iodinated contrast media "MD-Gastroview" (Guerbet)@90ml was administered (PO). After 3, 5, and 10 minutes of oral administration of contrast agent, a series of radiographs were taken in all dogs of group $\mathrm{A}, \mathrm{B}$ and $\mathrm{C}$ to assess the any obstruction or leakage in normal passage of stomach and accumulation of fluid in stomach. Post-operative leakage was found in dogs of group B and C. Pyloric obstruction was missing in dogs of all groups.

Table 8: Contrast Radiographic Observations for leakage of Group A, B and C

\begin{tabular}{llll} 
Days & $\begin{array}{l}\text { Group A } \\
\text { (Leakage) }\end{array}$ & $\begin{array}{l}\text { Group B } \\
\text { (Leakage) }\end{array}$ & $\begin{array}{l}\text { Group C } \\
\text { (Leakage) }\end{array}$ \\
\hline 1 & Absent & Absent & Absent \\
3 & Absent & Absent & Absent \\
\hline 5 & Absent & Present in 1 dog & Absent \\
7 & Absent & Absent & Present in 1 dog \\
\hline 15 & Absent & Absent & Absent \\
30 & Absent & Absent & Absent \\
45 & Absent & Absent & Absent \\
60 & Absent & Absent & Absent \\
\hline
\end{tabular}

Values carrying ${ }^{\circ}$ superscript indicates that dogs with leakage expired during study

The results from the contrast radiography showed that there was no leakage in any group till day 5 post-operation. In group B leakage in one dog was present at day 5 which later died. In group $\mathrm{C}$, one animal showed leakage at day 7 post-operation and the dog expired due to blood loss and peritonitis. In group A, all dogs remained fine.

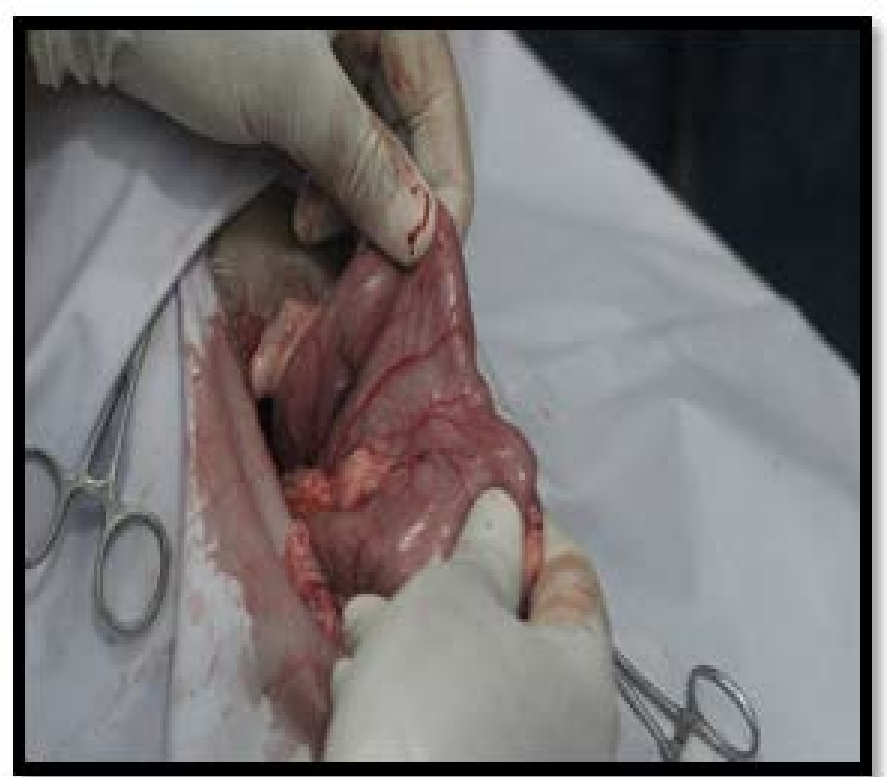

Figure 1: Gastrotomy Incision Site

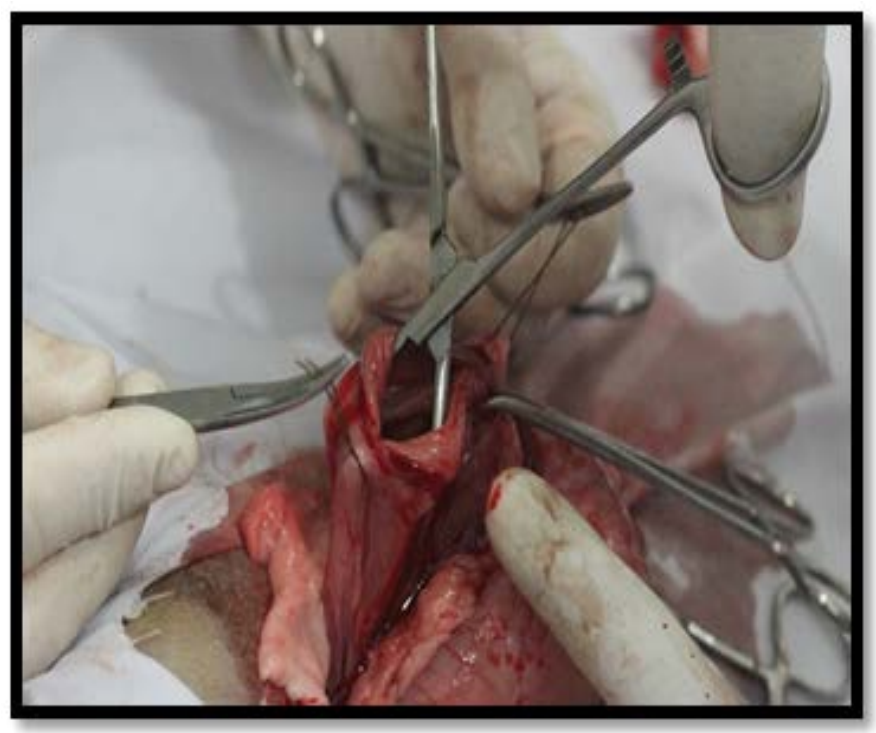

Figure 2: Gastrotomy Incision

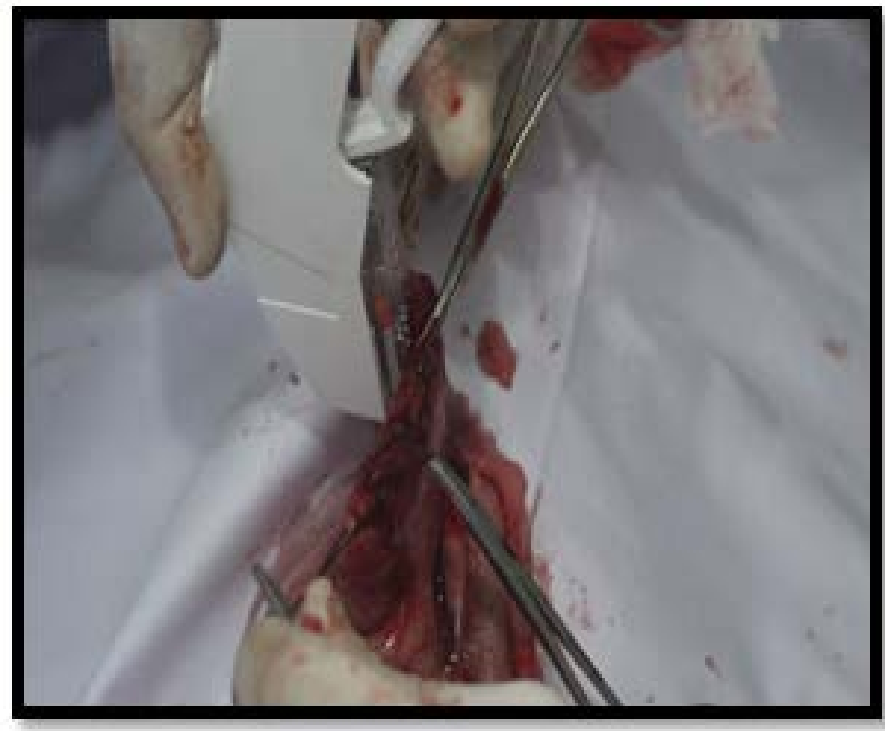

Figure 3: Stapling for Gastrotomy Incision Closure.

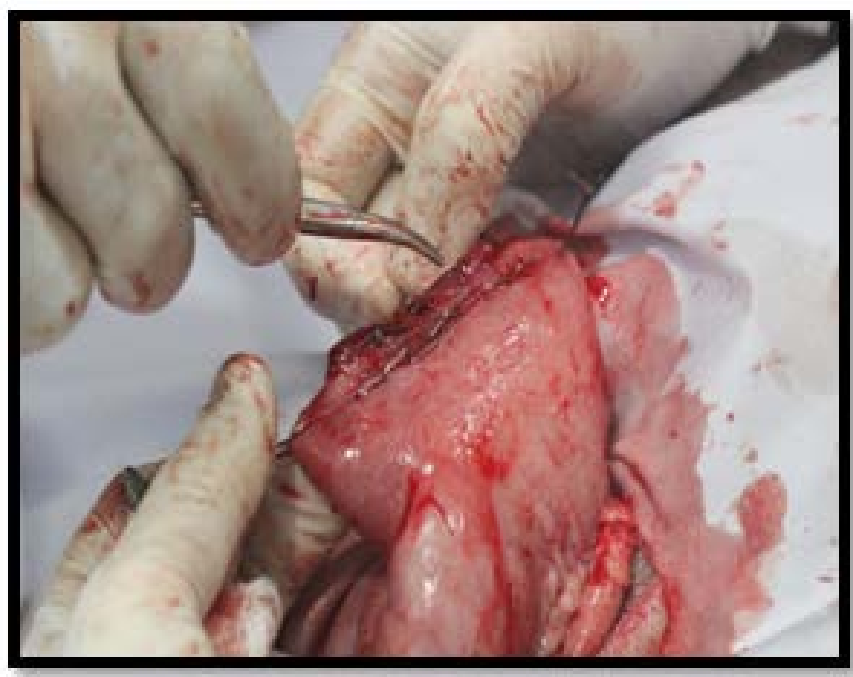

Figure 4: Stapling Suture Closure View 


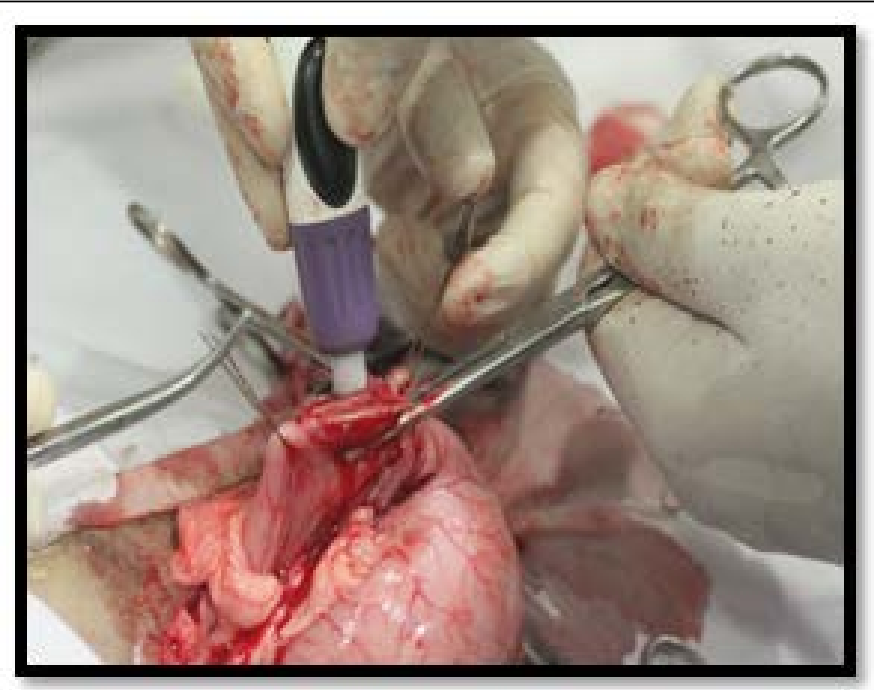

Figure 5: Surgical Glue for incision Closure.

\section{DISCUSSION}

The present study was undertaken to compare the best surgical technique for gastrotomy closure in various pathological condition of stomach that may require gastrotomy (Slatter, 2003). The clinical trials were conducted to compare three techniques of gastrotomy closure which included conventional sutures, surgical glue and stapling apposition of gastric incision and various parameters were analyzed to compare their efficacy at day 1, 3, 5, 7, 15, 30, 45 and 60. Topographic approach for physical evaluation of stomach in current study was similar to that stated by (Performing the Small Animal Physical Examination (1st Ed.) p.346). Temperature, pulse $\&$ respiration were checked to evaluate general health status which indicated no significant difference between groups. Graphical presentation of these parameters coincided with (Introduction to Health Science Technology-2nd Edition p. 423-25).

It was observed that dogs of Group A showed better results in terms of healing with least post-operative complication when suturing was applied e.g., stenosis and peritonitis etc., than group $\mathrm{B}$ and $\mathrm{C}$ that were suture less and do not have proper adhesion.

Hematology analysis revealed that there was significant difference between groups in terms of WBCs, RBCs and $\mathrm{Hb}$. White blood cells level remained elevated from day 3 to day 7 in group $\mathrm{A}$ and $\mathrm{C}$ and subsequently declined to normal levels till end of trial. WBCs in group B remained at persistently upper level till day $30 \&$ showed gradual decrease till day 60 . These values indicate persistence of gastric infection/contamination in group B for long periods, in group $\mathrm{C}$ was at moderate levels while group $\mathrm{A}$ showed least contamination/infection. RBC values revealed that group $\mathrm{A}$ showed best results as its values were consistent and gradually elevated from day 7 to end of trial, in group B values showed decline from day 5 to day $30 \&$ then raised slightly till day 60 , in group $C$ values declined at day 3 , slightly raised \& fluctuated from day 5 to day 30 and eventually elevated till end of experiment. Haemoglobin levels indicate that values of Group A slightly fluctuated up to day 7 and then rose from day $15 \&$ remained persistent till day 60 , in group B values slightly declined till day $30 \&$ then elevated slightly till end of trial, group $\mathrm{C}$ relatively showed persistence for the whole period with slight elevation seen towards end of experiment. These blood parameters were in co incidence with (Wintrobe's Clinical Hematology Thirteenth Edition). Gain/loss in body weight revealed that there was significant difference between groups. Group A showed better results in weight gain, its weight dropped till day 7 then dogs started regaining it till end of trial, group B showed sharp decrease till day 15 , then slight increase was observed till end of experiment, group $\mathrm{C}$ also showed pattern like group A till day 7 , onward slight increase was seen till day $45 \&$ then again slight decrease seen till day 60. It indicates that Group A showed better weight recovery than group $\mathrm{B}$ and $\mathrm{C}$ due to proper healing. The results from the contrast radiography showed that there was no leakage in any group till day 5 post-operation. In group B leakage in one dog was present at day 5 which later died. In group $\mathrm{C}$, one animal showed leakage at day 7 post-op. and the dog was expired due to blood loss and peritonitis. In group A, all dogs remained fine.

\section{CONCLUSION}

It was noted that all the three closure techniques which we used in this project were clinically successful. The dogs of all group survived except $\operatorname{dog}$ number 8 of group B and dog Number 11 of group $\mathrm{C}$ which did not complete the study and died on postoperative day 5 th and day 7 th respectively. This was due to leakage, anemia and strangulation of splenic blood supply post operatively. However, remaining dogs returned to its normal gastric flow and physical activity after observation period. To conclude, it was observed that dogs of Group A showed better results in terms of healing with least post-operative complication when suturing was applied e.g., stenosis and peritonitis etc., than group $\mathrm{B}$ and $\mathrm{C}$ that were suture less and do not have proper adhesion. Group C showed better results than group B, with minimum fibrosis, least stenosis and better healing time. According to our findings though stapling may be a good appositional method but somewhat less better than adhesive glue, because of difficulty to fire, more prone to stenosis with increased risk of infection at stapling site.

\section{CONFLICT OF INTEREST}

there is no conflict of interest. 


\section{AUTHORS CONTRIBUTION}

Muhammad Atif, Naveed Hussain, Nasir Iqbal, Sadaf Aslam, Haroon Akbar, Ayesha Sadiq: Experimental Trial and Revision. Zahra Ashraf, Zubair Luqman, Hamza Jawad: Formatting, Setting and Revision.

\section{REFERENCES}

- Belandria GA, Pavletic MM, BoulayJP, Penninck DG, Schwarz LA (2009).

- Cerdá DG, Ballester AM, Aliena-Valero A, Carabén-Redaño A, Lloris JM (2015). Use of cyanoacrylate adhesives in general surgery. Surgery today. 45(8): 939-956. https://doi. org/10.1007/s00595-014-1056-4

- Coolman BR, Ehrhart N, Pijanowski G, Ehrhart EJ, Coolman SL (2000). Comparison of skin staples with sutures for anastomosis of the small intestine in dogs. Vet. Surg. 29(4): 293-302. https://doi.org/10.1053/jvet.2000.7539

-DePompeo CM, Bond L, George YE, Mezzles MJ, Brourman JD, Chandler JC, Mason DR (2018). Intra-abdominal complications following intestinal anastomoses by suture and staple techniques in dogs. J. American Vet. Med. Assoc. 253(4), 437-443. https://doi.org/10.2460/ javma.253.4.437

-Eason BD, Hogan DF, Lim C, Hogan MJ (2017). Use of n-butyl cyanoacrylate to reduce left to right shunting of an abdominal arteriovenous malformation in a dog. J. Vet. Cardiol. 19(4): 396-403. https://doi.org/10.1016/j.jvc.2017.05.002

- Formaggini L, Degna MT (2018). A Prospective Evaluation of a Modified Belt-Loop Gastropexy in 100 Dogs with Gastric Dilatation-Volvulus. J. American Anim. Hosp. Assoc. 54(5): 239-245. https://doi.org/10.5326/JAAHA-MS-6596

- Simmers LM (2008). Introduction to health science technology. Cengage Learning.

- Schwartz Z, Coolman BR (2018). Disposable skin staplers for closure of linear gastrointestinal incisions in dogs. Vet. Surg. 47(2): 285-292. https://doi.org/10.1111/vsu.12759

- Slatter DH (Ed.). (2003). Textbook of small animal surgery (Vol. 1). Elsevier Health Sciences.

- Sogi KBC, Kumar P, Kailas CT, Chandrasekhar RL (2019). Isoamyl-2-cyanoacrylate with subcuticular polyamide suture for skin closure in elective surgical procedures: Comparison of cosmetic outcome. Int. J. Surg. 3(1): 33-36. https://doi. org/10.33545/surgery.2019.v3.i1a.10

-Wintrobe MM (2008). Wintrobe's clinical hematology (Vol. 1). Lippincott Williams \& Wilkins. 